\title{
Metacognition and motivation in mathematical problem solving
}

\begin{abstract}
otivation (O'Neil \& Schacter, 1997). Based on the proposed model of problem solving, students' content understanding and problem-solving strategies were identified through interviews. The other two elements were identified using a survey instrument. This paper reports findings of the survey instrument that focuses on determining (i) students' level of motivation and level of metacognition in solving mathematical problems, (ii) relationship between level of motivation and level of metacognition with mathematics achievement and overall academic achievement, and (iii) determining relationship between motivation and metacognition. The subjects of this study were 195 final year students majoring in mathematics education. Metacognition refers to the ability of individuals to reflect, understandand control their own learning (Schraw \& Dennison, 1994). Specific components of metacognitive processes were identified by Schraw \& Dennison (1994) and these were the dimensions that they used in developing the Metacognitive Awareness Inventory (MAI). MAI that comprises of 52 items is a reliable measure of cognition and regulation of cognition (Sanchez-Alonso \& Vovides, 2006). It measures eight specific components of metacognition; namely comprehension monitoring, procedural knowledge, declarative knowledge, conditional knowledge, evaluation, debugging strategies, information management strategies and planning. In O'Neil and Schacter's (1997) study, metacognition was measured using three elements; planning, self-checking and cognitive strategy. MAI was used because it includes more elements that reflect one's metacognitive strategies. Apart from MAI, subjects were also required to respond to the measurement used by O'Neil and Schacter's (1997) to measure motivation. The elements in measuring motivation are effort, self-efficacy, and worry. Three dimensions of MAI; procedural, declarative and conditional knowledge were found to be significantly correlated with students' performance in university mathematics courses. Declarative and conditional knowledge were also found to be significantly correlated with students' overall performance in the university. All three dimensions of motivation were also found to be significantly correlated with performance in university mathematics courses. Significant correlation was also established between level of metacognition with level of motivation. In conclusion, this study reveals some of the factors that influence one's performance in mathematical problem solving.
\end{abstract}

Keyword: Metacognition, Motivation, Mathematical Problem Solving 